\title{
Neural Model of Projecting Compressive Strength of Cement Concrete Intended for Airfield Pavements
}

\author{
Małgorzata Linek \\ Kielce University of Technology, Faculty of Civil Engineering and Architecture, Department of \\ Transportation Engineering, Aleja Państwa Polskiego Street 7,25-314 Kielce, Poland, tel.+48 41 \\ 3424844, e-mail: linekm@tu.kielce.pl
}

\begin{abstract}
This work present to the mathematical model in the form of ANN, intended for projecting concrete compressive strength. Input data was classified according to the type of component material and its content in concrete mix (cement contents, coarse aggregate, fine aggregate, water and admixtures). In order to determine mathematical model, a multilayer, one-way perceptron network was used, recursion network with sigmoidal neurons. The model assumes that neurons are gathered in some layers (one input layer, hidden layers and one output layer). The conducted cross-section of the influence of variables parameters values (learning constant - $\alpha$ and momentum values - $\eta$ ) on the accuracy of representation of compressive strength was analyses. Assessment criterion was assumed taking into consideration the lowest mistake level and 100\% compliance. According to the obtained analysis results ANN was assumed the best representing network for constant value of momentum 0,3, learning constant of 0,05 and 6 neurons in a hidden layer. Very good coincidence of component models with experiment results was achieved. At testing stage, the coincidence was achieved at the level of $99.74 \%$, in case of the assumed network structure. During model verification by means of experimental results, the average coincidence was $99.83 \%$.
\end{abstract}

Keywords: Compressive Strength, Cement Concrete, Airfield Pavements, Neural Model, Artificial Neural Networks.

\section{Introduction}

The knowledge of mathematical model defining concrete resistance depending on the type of components and contribution thereto is interesting in terms of science and practice. Using Artificial Neural Networks (ANN) for this purpose and the opportunity to apply thereof for communications engineering and its particular applications are of the main interests of researchers of this field and construction branch in its general aspects. Potential capacities of ANN were proved, among others, in the following works (Bayrak et al., 2009; Bishop, 1995; Ceylan et al., 2007; Kasperkiewicz, 2004; Kim et al., Manerowski et al., 2006; Waszczyszyn, 2001). This work is an attempt to use ANN in order to design concrete mixtures intended for airfield pavements, define properties of hardened concrete and project the strength thereof. ANN provide the opportunity of structural dimensioning of susceptible and rigid pavements (e.g. Bilgehan et al., 2010; Ceylan et al., 1684; Ioannides et al., Noorzaei et al., 2007; Pożarycki, 2012; Thanoon et al., 2007; Urbańska et al., 2002). Using own collected database containing strength, laboratory test results, the mathematical model in the form of ANN, intended for projecting concrete strength, was presented. The essence of ANN is the selection of network structure (the number of layers and the number of neurons in particular layers) and defining the parameters thereof (constant values and weights). 


\section{Materials and Methods}

This research paper concerns the issue of projecting the compressive strength of concrete intended for airfield pavements as far as structure durability is concerned. As a result of own laboratory and field tests (e.g. Linek et al., 2016; Linek, 2017; Linek et al., 2018), the strength of concrete containing various components of diversified contents were determined.

Consequently, the significant database was collected which enabled to prepare mathematical model allowing to determine concrete strength. Application of ANN resulted from the necessity to identify the diversification of compressive strength, which was the effect of changes in case of aggregate composition of concrete mix. One of the basic parameters of hardened concrete, which has the direct influence on the durability thereof in case of airfield pavement, is compressive strength (Glinicki, 2011; Nita, 2005; Szydło, 2004). This property depends on the diversified factors, among which there are the cement type and content, amount of coarse and fine aggregate and agents added to the mix aimed at the improvement of its parameters, and consequently also the parameters of hardened concrete. In case of each out of 6500 mixes, coarse and fine aggregate.

The aggregate should be distinguished by high durability and frost resistance, abrasion and polishing resistance and low absorbability. The designed aggregate compositions each time complied with (PN-EN 206-1:2003) and (NO 17A 204:2015). Mix composition included clean-clinker Portland cement in various amounts CEM I 42,5 (which fulfilled the requirements of (PN-EN 197-1)) and water (complied with (PN-EN 1008:2004)), designing

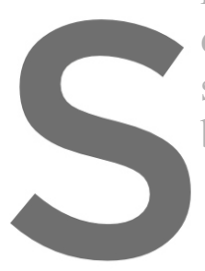
diversified water-content ratio with reference to
significantly influences concrete durability. Lim
been presented in the table 1 .
Table 1 . Limit component contents of the an

Elements content Cement Coarse aggregate

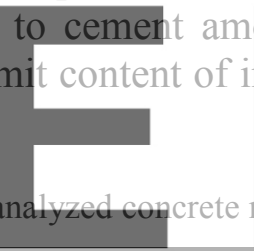
Fine aggregate
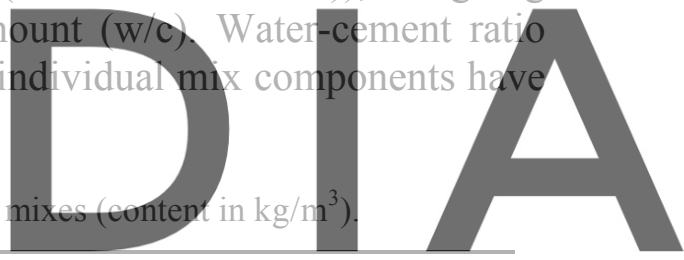

Register for free at hetes//WWww.Scipedia.com to download the version without the watermark

On the $28^{\text {th }}$ day since concreting, each sample, prepared and cured in accordance with the requirements of (PN-EN 12390-2:2009), was subject to destructive tests by means of hydraulic press in compliance with (PN-EN 12390-4:2009). Maximum force destructing the sample, obtained according to the measurements, taking into consideration the assumed constant loading speed of $0,5 \mathrm{MPa} / \mathrm{s}$, was the basis for defining compressive strength of individual samples. The subject of further analyses included the samples which proved proper nature of destruction, after destructive test, according to (PN-EN 12309-3:2009). In case of each sample the compressive strength $-f_{c}$ was determined, according to $\mathrm{f}_{\mathrm{c}}=\mathrm{F} / \mathrm{A}_{\mathrm{c}}$, where $F$ refers to maximum load registered in the course of sample destruction, while $A_{C}$ refers to cross-sectional area of the sample which is influenced by the compressive force. The strength values obtained in this way were the input base to assess compressive strength of cement concrete intended for airfield pavements using ANN. All obtained test results concerning individual research series corresponded to the assumptions of the designed concrete classes and they were statistically essential. Therefore, they were the reliable source of input data for ANN identification, reflecting concrete strength in case of various compositions thereof. 


\section{Data Preparation}

Operation of neural network depends on the type of neuron which will be accepted. Among the most commonly used, there are linear neurons, MLP, RBF, GRNN and Kohonen (Ossowski, 2006; Tadeusiewicz, 1993). Neuron used in the course of network designing process consists of output signal being the total of constant and relevant input signals multiplied by weight. Output signal structure in case of the analyzed network has been presented as follows (1):

$$
y_{i}=S_{i}+\bar{X}_{l}(i, i) \overline{w^{T}}(i, i)
$$

In case of equation (2) input signals take the form of $\bar{X}_{l}=\left[x_{\mathrm{i} 1}, x_{\mathrm{i} 2} \ldots x_{i n}\right]$, while the corresponding weights $\overline{w_{l}}=\left[w_{\mathrm{i} 1}, w_{\mathrm{i} 2} \ldots w_{i n}\right]$. The essence of the prepared network is to determine individual weights and constants $S_{\mathrm{i}}$. Due to the fact that neurons have learning opportunities, synaptic scales were used, which can provide variable values and which are the basis for network learning. The applied activation function was presented by means of the following: $\mathrm{F}\left(\mathrm{y}_{\mathrm{i}}\right)=1 /\left(1+\exp \left(-2 \mathrm{y}_{\mathrm{i}}\right)\right)$. The assessment of representation accuracy of values from the experiment and coefficients generated by neural network was defined on the basis of two parameters. The first one is the average of the sum of squares of differences between the values of outputs from the real structure $\left(\mathrm{y}_{\mathrm{rz}}\right)$ and model $(\mathrm{N})$ for experimental data $(\mathrm{i}=1,2$,

\section{N). The sum of squares of differences was determined according to the relationship (2).}
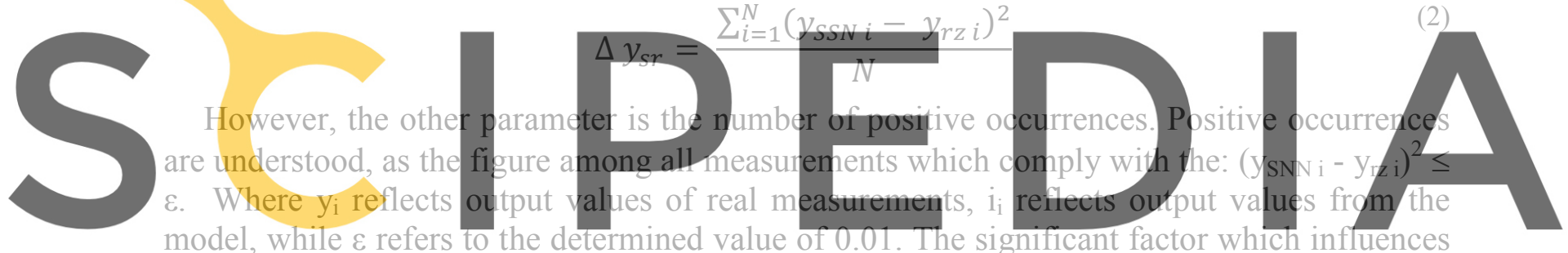

model, while $\varepsilon$ refers to the determined value of 0.01 . The significant factor which influences the accuracy of projection of concrete strength by ANN is creating representative input

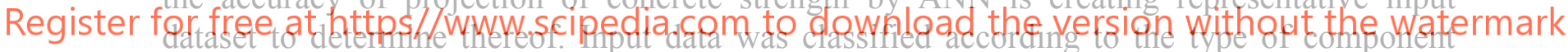

material and its content in concrete mix. The following material types were considered: 9 types of cement, 17 types of coarse aggregate, 2 types of fine aggregate, 5 types of additives and 6 types of mix consistency as technological parameter, influencing proper structure performance related process. There were 6500 of diversified mix compositions collected, out of which $70 \%$ was assumed as input database for ANN, 15\% was intended for testing purposes of the educated network, and the remaining $15 \%$ for network verification.

The selection of network structure is determined by the opportunity of feedback occurrence. These issues, among others, have been discussed in detail in the following work (Haykin, 1994), and their essence is the occurrence or absence of return connection (from latter to previous neurons), according to recursion and one-way structure. For the research paper purposes it was assumed that the feedbacks will not occur. Figure 1 presents schematic normalization process of input signals $X$ and output signals y performed using ANN of the subject research paper. The results obtained as part of the conducted actual laboratory experiments were considered as the data. In case of the data which was subject to normalization, neural network was determined and then dimensional values thereof were calculated. In order to determine mathematical model, a multilayer, one-way perceptron 
network was used, recursion network with sigmoidal neurons using JETNET 2.0 program (Lónnblad et al., 1992). The software used for network learning includes algorithm of moment method of backward mistake propagation (Rutkowski, 2005). ANN structure was presented in Figure 2. The data collected in the course of experiments was referred to as input layer of the prepared model. Input layer included 5 elements corresponding to individual cement contents $(\mathrm{C})$, coarse aggregate $(\mathrm{Kg})$, fine aggregate $(\mathrm{Kd})$, water $(\mathrm{W})$ and admixtures (D). The model assumes that neurons are gathered in some layers, among which there is one input layer, hidden layers and one output layer. It was assumed that input signals will be subject to normalization and have numeric values from 0 to 1 . Among the available methods (among others min-max, Z-score, zero-mean, decimal calibration) normalization was selected in accordance with linear initial data transformation in compliance with: $\bar{x}_{l}=\left(x_{i}-\right.$ $\left.x_{\min }\right) / \Delta x$, where $\bar{x}_{l}$ refers to normalized data, $\mathrm{x}_{\mathrm{i}}-$ particular real values, $\mathrm{x}_{\min }-$ minimum value of real values, while $\Delta \mathrm{x}$ refers to the difference between maximum and minimum value, $\mathrm{i}=1,2, \ldots, 5$. Analogously for the output data in compliance with: $\overline{y_{l}}=\left(y_{i}-y_{\min }\right) / \Delta x$.
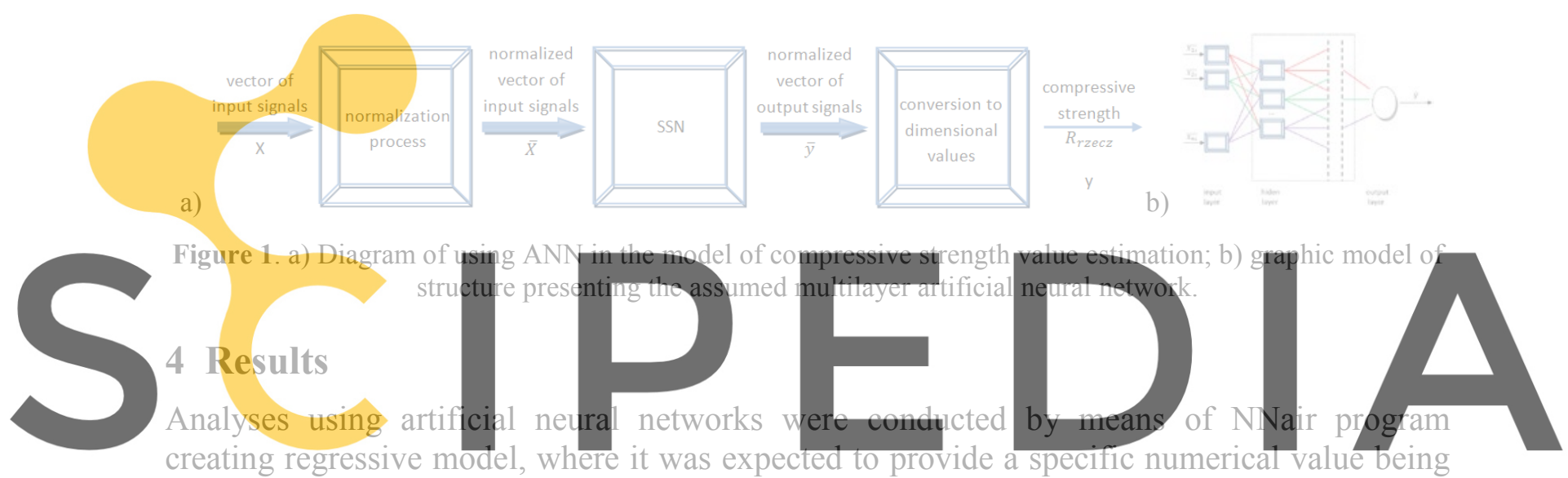
creating regressive model, where it was expected to provide a specific numerical value being the solution to the problem. In case of the analyzed case this value.was identified with the

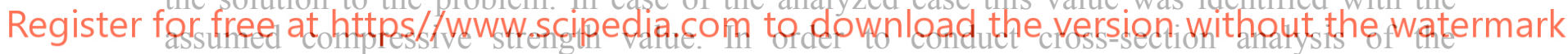

influence of variables parameters values ( $\alpha$ and $\eta$ ) on the accuracy of representation of compressive strength, analyses including matrix of $90 \times 90$ elements. According to the obtained results it was proved that the selection of $\alpha$ and $\eta$ has significant influence on the extent of the obtained representation.

Table 2. Influence of learning constant value $\alpha$ on the accuracy of compressive strength representation (assuming constant value of momentum $\eta=0.3$ and $\varepsilon=0.01$ ).

\begin{tabular}{|c|c|c|c|c|c|c|c|}
\hline $\begin{array}{l}\text { No } \\
\text { ANN }\end{array}$ & $\alpha$ & $\eta$ & $\begin{array}{c}\text { Number of } \\
\text { inputs }\end{array}$ & Number of neurons & $\begin{array}{l}\text { Number of } \\
\text { outputs }\end{array}$ & $\begin{array}{c}\text { Percentage of } \\
\text { positive events }\end{array}$ & $\Delta \mathrm{y}_{\mathrm{sr}}$ \\
\hline $1-1$ & 0.03 & 0.3 & 5 & 5 & 1 & 100 & 0.0034718 \\
\hline $1-2$ & 0.04 & 0.3 & 5 & 5 & 1 & 100 & 0.0031399 \\
\hline $1-3$ & 0.05 & 0.3 & 5 & 5 & 1 & 100 & 0.0028273 \\
\hline $1-4$ & 0.06 & 0.3 & 5 & 5 & 1 & 99.6 & 0.0025851 \\
\hline $1-5$ & 0.07 & 0.3 & 5 & 5 & 1 & 99.4 & 0.0024215 \\
\hline
\end{tabular}


Table 3. Influence of momentum value $\alpha$ (from 0.3 to 0.7 ) on the accuracy of compressive strength representation (assuming constant learning constant value of learning constant $=0.04$ and $\varepsilon=0.01$ ).

\begin{tabular}{cccccccc}
\hline $\begin{array}{c}\text { No } \\
\text { ANN }\end{array}$ & $\alpha$ & $\eta$ & $\begin{array}{c}\text { Number of } \\
\text { inputs }\end{array}$ & Number of neurons & $\begin{array}{c}\text { Number of } \\
\text { outputs }\end{array}$ & $\begin{array}{c}\text { Percentage of } \\
\text { positive events }\end{array}$ & $\Delta \mathrm{y}_{\mathrm{sr}}$ \\
\hline $2-1$ & 0.04 & 0.30 & 5 & 4 & 1 & 99.6 & 0.0023666 \\
\hline $2-2$ & 0.04 & 0.40 & 5 & 4 & 1 & 99.4 & 0.0023475 \\
\hline $2-3$ & 0.04 & 0.50 & 5 & 4 & 1 & 99.4 & 0.0023339 \\
\hline $2-4$ & 0.04 & 0.60 & 5 & 4 & 1 & 98.2 & 0.0023255 \\
\hline $2-5$ & 0.04 & 0.70 & 5 & 4 & 1 & 97 & 0.0023281 \\
\hline
\end{tabular}

Table 4. Influence of neurons number (5-10) in a hidden layer on the accuracy of representation of compressive strength at constant value of momentum 0.4 , learning constant 0.03 and $\varepsilon=0.01$.

\begin{tabular}{|c|c|c|c|c|c|c|}
\hline \multirow{2}{*}{$\begin{array}{c}\text { percentage of } \\
\text { positive } \\
\text { events }\end{array}$} & \multicolumn{6}{|c|}{ the number of neurons in the hidden layer } \\
\cline { 2 - 7 } & 5 & 6 & 7 & 8 & 9 & 10 \\
\hline$\Delta y_{S r}$ & 0.0028273 & 0.0022759 & 0.0031341 & 0.0022653 & 0.0027379 & 0.014378 \\
\hline
\end{tabular}

Analyzing the data presented in table 2 and 3, the initial tolerance of learning constant was assumed at 0.05 and the initial tolerance of momentum was assumed at 0.3 for further analyses. In case of such assumed tolerance, the least value of the generated mistake, at the highest compliance of results was obtained.
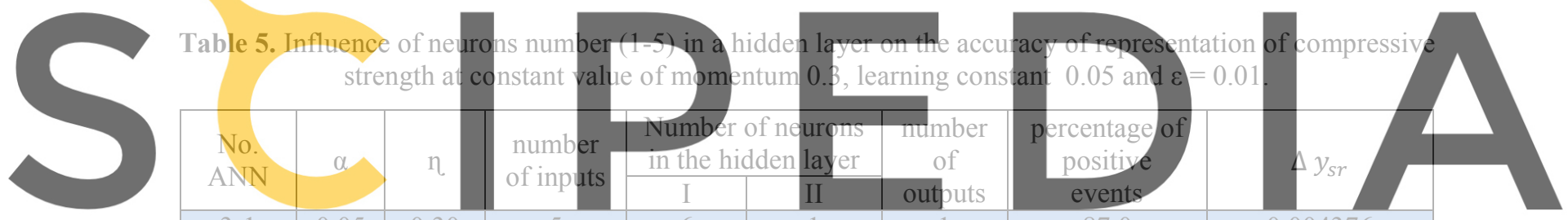

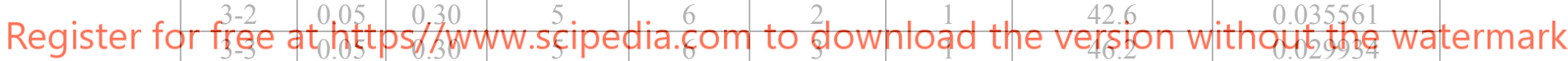

\begin{tabular}{|l|l|l|l|l|l|l|l|l|}
\hline $3-4$ & 0.05 & 0.30 & 5 & 6 & 4 & 1 & 42.6 & 0.034757 \\
\hline $3-5$ & 0.05 & 0.30 & 5 & 6 & 5 & 1 & 46.2 & 0.028068 \\
\hline $3-6$ & 0.05 & 0.30 & 5 & 1 & 6 & 1 & 42.6 & 0.031157 \\
\hline $3-7$ & 0.05 & 0.30 & 5 & 2 & 6 & 1 & 46.2 & 0.028427 \\
\hline $3-8$ & 0.05 & 0.30 & 5 & 3 & 6 & 1 & 46.2 & 0.030317 \\
\hline $3-9$ & 0.05 & 0.30 & 5 & 4 & 6 & 1 & 87.0 & 0.004865 \\
\hline $3-10$ & 0.05 & 0.30 & 5 & 5 & 6 & 1 & 42.6 & 0.033186 \\
\hline
\end{tabular}

According to the obtained analysis results ANN (tab. 4, 5) was assumed the best representing network for constant value of momentum 0.3 , learning constant of $0.05,6$ neurons in a hidden layer and assumed $\varepsilon=0.01$. In case of network of 5-6-1 structure, the first digit (5) refers to the number of inputs, next (6) the number of neurons in a hidden layer, and the last one (1) refers to one output identified with the assumed compressive strength value. This structure was assumed as a result of accuracy tests of representing real compressive strength values by the network. Assessment criterion was assumed taking into consideration the lowest mistake level and 100\% compliance. Figure 3 presents the courses of learning in case of network of 6 neurons in a hidden layer. It can be observed that minimum values 
$\Delta y_{s r}$ amount to 0.008 , and maximum values amount to 0.520 in case of the assumed number of iterations. According to the obtained results of ANN analysis it was proved that the determined network can be recognized reliable for 38000 iterations.

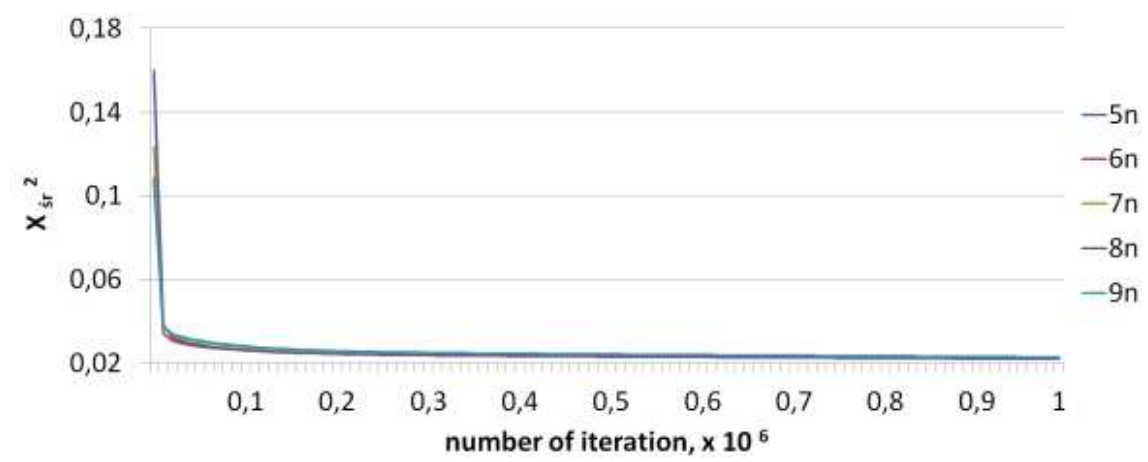

Figure 3. The course of learning process by ANN of diversified neurons number in a hidden layer.

Table 6 presents approximate contents of individual mix components intended for network testing. Figure 4(a) presents graphic summary of data determined at testing stage by the educated network. According to the obtained characteristics (Tab. 7 and Tab. 8) it was proved that the testing and verification of artificial neural network model reflects the values determined by the network. The obtained average value from 1300 events coincidence over $99 \%$ is very high. Average value of coincidence is $99.08 \%$. The obtained average value from
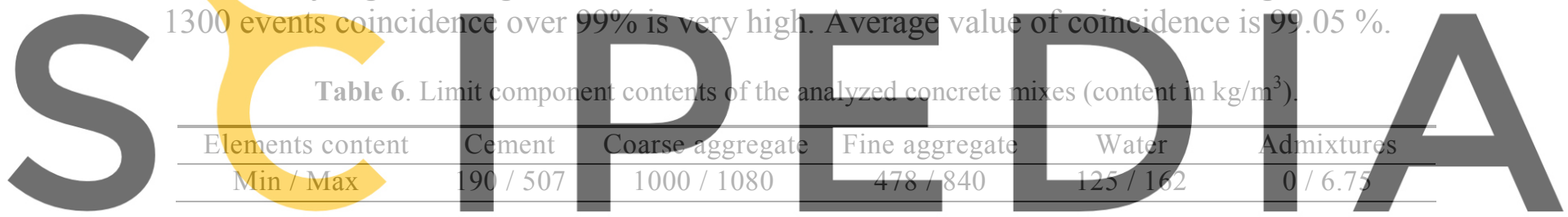

Table 7. Testing of ANN model (N-value determined from the network, $\mathrm{T}$ - value determined during testing).

Register for free at https//www.scipedia.com to download the version without the watermark

\begin{tabular}{|c|c|c|c|c|c|c|c|c|}
\multirow{2}{*}{ No } & \multicolumn{9}{|c|}{ Input data } & \multicolumn{3}{c|}{ Output data } \\
\cline { 2 - 9 } & {$\left[\mathrm{kg} / \mathrm{m}^{3}\right]$} & {$\left[\mathrm{kg} / \mathrm{m}^{3}\right]$} & {$\left[\mathrm{kg} / \mathrm{m}^{3}\right]$} & {$\left[\mathrm{kg} / \mathrm{m}^{3}\right]$} & {$\left[\mathrm{kg} / \mathrm{m}^{3}\right]$} & {$[\mathrm{MPa}]$} & {$[\mathrm{MPa}]$} & {$[\%]$} \\
\hline 1. & 324 & 1009 & 821 & 130 & 0.4 & 38.8 & 38.8 & 100.00 \\
\hline 2. & 386 & 1391 & 744 & 154 & 1.7 & 38.9 & 38.9 & 100.00 \\
\hline 3. & 424 & 1286 & 683 & 127 & 1.5 & 39.8 & 39.7 & 99.75 \\
\hline 4. & 350 & 1334 & 698 & 140 & 2.2 & 37.7 & 37.5 & 99.47 \\
\hline 5. & 434 & 1313 & 686 & 174 & 0.6 & 38.2 & 37.9 & 99.21 \\
\hline 6. & 437 & 1371 & 684 & 175 & 2.0 & 33.5 & 33.5 & 100.00 \\
\hline 7. & 390 & 1287 & 724 & 156 & 2.9 & 28.2 & 28.2 & 100.00 \\
\hline 8. & 400 & 1346 & 642 & 162 & 2.3 & 39.0 & 39.1 & 99.74 \\
\hline 9. & 368 & 1323 & 748 & 147 & 2.5 & 39.4 & 39.2 & 99.49 \\
\hline 10. & 356 & 1155 & 566 & 142 & 1.5 & 37.6 & 37.5 & 99.73 \\
\hline
\end{tabular}

The educated and tested ANN network of 5-6-1 structure was intended for experimental verification. Figure 4(b) presents graphic summary of data determined at verification stage by the educated network. Table 8 includes the obtained selected analyses results. 
a)

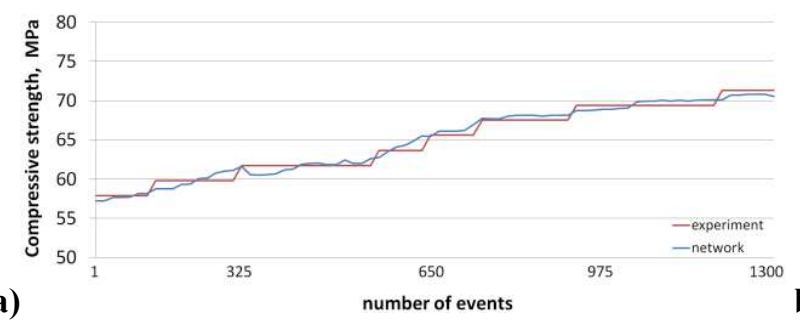

b)

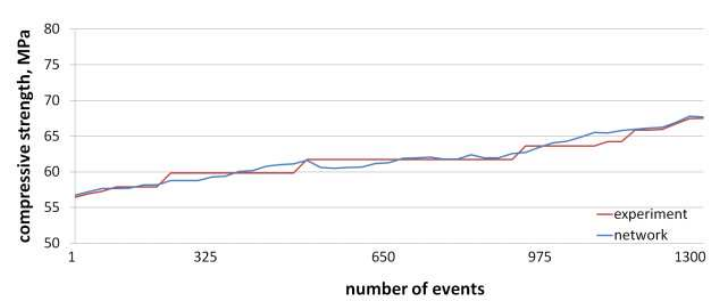

Figure 4. The course of (a) testing process and (b) verification neural networks of 5-6-1 structure.

Table 8. ANN model verification (N-value determined from the network, $\mathrm{T}$ - value determined during testing).

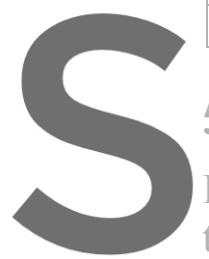

\begin{tabular}{|c|c|c|c|c|c|c|c|c|}
\hline \multirow{3}{*}{ No } & \multicolumn{5}{|c|}{ Input data } & \multicolumn{3}{|c|}{ Output data } \\
\hline & $\mathrm{C}$ & $\mathrm{Kg}$ & $\mathrm{Kd}$ & $\mathrm{W}$ & D & $\mathrm{N}$ & $\mathrm{T}$ & accuracy \\
\hline & {$\left[\mathrm{kg} / \mathrm{m}^{3}\right]$} & {$\left[\mathrm{kg} / \mathrm{m}^{3}\right]$} & {$\left[\mathrm{kg} / \mathrm{m}^{3}\right]$} & {$\left[\mathrm{kg} / \mathrm{m}^{3}\right]$} & {$\left[\mathrm{kg} / \mathrm{m}^{3}\right]$} & {$[\mathrm{MPa}]$} & [MPa] & {$[\%]$} \\
\hline 1. & 353 & 1096 & 675 & 141 & 0.4 & 34.1 & 34.2 & 99.75 \\
\hline 2. & 390 & 1402 & 667 & 156 & 0.7 & 37.6 & 37.5 & 99.54 \\
\hline 3. & 399 & 1199 & 733 & 159 & 0.8 & 26.8 & 26.7 & 99.63 \\
\hline 4. & 380 & 1305 & 677 & 152 & 0.8 & 34.2 & 34.2 & 100.00 \\
\hline 5. & 346 & 1242 & 771 & 138 & 1.3 & 38.0 & 37.9 & 99.77 \\
\hline 6. & 404 & 1244 & 699 & 161 & 1.5 & 36.4 & 36.4 & 100.00 \\
\hline 7. & 444 & 1182 & 795 & 178 & 2.2 & 37.5 & 37.4 & 99.77 \\
\hline 8. & 417 & 1318 & 743 & 166 & 2.4 & 33.0 & 33.0 & 100.00 \\
\hline 9. & 359 & 1207 & 591 & 143 & 2.7 & 37.9 & 37.8 & 99.77 \\
\hline 10. & 379 & 1402 & 592 & 151 & 2.8 & 36.2 & 36.2 & 100.00 \\
\hline
\end{tabular}

The results obtained as a result of the conducted analyses prove the purpose of application

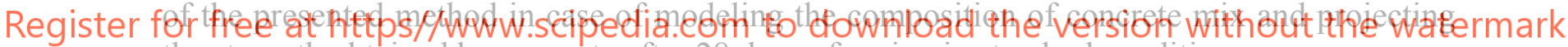
the strength obtained by concrete after 28 days of curing in standard conditions.

The analyzed structure 5-6-1 allows drawing the conclusions regarding material parameters even in case of limited number of elements. Based on the obtained results, the network structure has a large influence on the accuracy of mapping results from the experiment through the network. The network analyzing five neurons in an input layer, diversified in terms the selection of hidden neurons amount, complies with model assumptions. It was proved that 5-6-1 network, with learning constant of 0.05 , momentum 0.3 and $\varepsilon=0.01$, is the most favorable structure for the assumed data. Very good coincidence of component models with experiment results was achieved. At testing stage, the coincidence was achieved at the level of $99.08 \%$, in case of the assumed network structure. During model verification by means of experimental results, the average coincidence was $99.05 \%$.

\section{ORCID}

Małgorzata Linek: http://orcid.org/0000-0003-1583-4377

\section{References}

Bayrak, M. and Ceylon, H. (2009). Neural Network-Based Approach for Analysis of Rigid Pavement Systems 
Using Deflection Data, Civil Construction and Environmental Engineering, 5.

Bilgehan, M. and Turgut, P. (2010). The use of neural networks in concrete compressive strength estimation, Computers and Concrete, 7 (3), 271-283.

Bishop, C. M. (1995) Neural Networks for pattern recognition. Oxford University Press, Oxford;

Ceylan, H. and Gopalakrishnan, K.(2007). Neural networksbased models for mechanistic-empirical design of rubblized concrete pavements, Geotechnical/Materials Engineering.

Ceylan, H., Tutumluer, E. and Barenberg, E. J. Artificial Neural Networks for Analyzing Concrete Airfield Pavements Serving the Boeing B777 Aircraft, Transportation Research record 1684, Paper No. 99-1199.

Glinicki, M. A. (2011). Durability of concrete in road surfaces. Effect of microstructure, materials design, diagnostics. Road and Bridge Research Institute, Warsaw, vol. 66.

Haykin. (1994). Neural Networks: A Comprehensive Foundation.

Ioannides, A. M., Alexander, D. R., Hammons, I. and Davis, C. M. Application of Artificial Neural Networks to Concrete Pavement Joint Evaluation, Transportation Research record 1540.

Kasperkiewicz, J. (2004). On the possibilities of using artificial intelligence methods in civil engineering, Roads and bridges, 3, 15-37.

Kim, S., Gopalakrishnan, K. and Ceylan, H. (2009). Neural Networks Application in Pavement Infrastructure Materials, Int. and Soft Comp. in Infrastr. Systems Eng., 259, Studies in Computational Intelligence, 47-66.

Linek, M. (2017). Low-shrink airfield cement concrete with respect to thermal resistance, MATEC Web of Conferences, 133, 07002, DOI: 10.1051/matecconf/201713307002.

Linek, M. and Nita, P. (2016). Maintenance of Airfield Pavements Made of Cement Concrete with Respect to Their Durability, Journal of KONES, 1, DOI: 10.5604/12314005.1213570

Linek, M., Nita, P., Wolka, P. and Żebrowski, W. (2018). Usefulness of porphyry and amphibolites as a component of concrete for airfield pavements, MATEC WoC, 163, 07002, DOI: 10.1051/matecconf/201816307002.

Lónnblad, L., Peterson, C. and Rógnvaldsson, T. (1992). Pattern recognition in high physics with artificial neutral networks - JET

Manerowski. J. and Zgrzy w artificial neural netwo Air Force Institute of

Nita, P. (2005). Concrete Technology, Warsaw
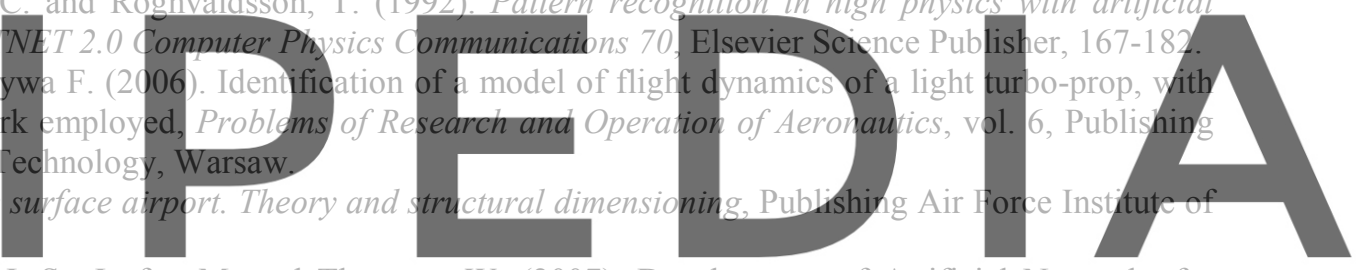

Noorzaei, J., Hakim, S. J. S., Jaafar, M. and Thanoon, W. (2007). Development of Artificial Networks for

Register fors predicting concrete compressive. strength, Int.J. of Engineering and Technology, $4(2), 141-153$. Publishing House, Warsaw.

Pożarycki A.(2012). Identification of the number and thickness of layers of the model of the new pavement of the test section by artificial intelligence methods (in Polish), Roads and Bridges, 2.

Rutkowski, L. (2005). Artificial intelligence methods and techniques (in Polish), PWN, Warsaw.

Szydło, A. (2004). Road surfaces made of cement concrete (in Polish), Polski Cement, Cracow.

Tadeusiewicz R.(1993). Neural networks (in Polish), Academic Publishing House RM, Warsaw.

Thanoon, W. A. M., J Noorzaei, SJS Hakim and MS Jaafar (2007). Development of Artificial Neural Networks for predicting concrete compressive strength, Int. J. of Engineering and Technology, 4, 141-153.

Urbańska A., Ligęza W. and Waszczyszyn Z. (2002). Analysis of concrete shrinkage using the RBF neural network (in Polish), XLVIII Scientific Conference, Krynica, 2002

Waszczyszyn, Z. (2001). Neural Networks in Structural Engineering. Some Recent Results and Prospects for Applications, Computational Mechanics for the New Millenium, Amsterdam, 1311-1320.

NO 17A 204 (2015).Airfield concrete pavements-Requirements and test methods for cement concrete pavements.

PN-EN 206-1 (2003). Concrete-Part 1: Specification, performance, production and conformity - Polish standard.

PN-EN 12390 (2009). Testing hardened concrete - Parts 2, 3 and 4 - Polish standard.

PN-EN 197-1 Cement part 1. Composition, specifications and conformity criteria for common cements.

PN-EN 1008 (2004). Mixing water for concrete-Specification for sampling, testing and assessing the suitability of water, including water recovered from processes in the concrete industry, as mixing water for concrete. 